\title{
Prognostic robustness of serum creatinine based AKI definitions in patients with sepsis: a prospective cohort study
}

\author{
Jill Vanmassenhove, Norbert Lameire, Annemieke Dhondt, Raymond Vanholder and Wim Van Biesen*
}

\begin{abstract}
Background: It is unclear how modifications in the way to calculate serum creatinine ( $\mathrm{s} C \mathrm{Cr}$ ) increase and in the cut-off value applied, influences the prognostic value of Acute Kidney Injury (AKI). We wanted to evaluate whether these modifications alter the prognostic value of AKI for prediction of mortality at 3 months, 1 and 2 years.

Methods: We prospectively included 195 septic patients and evaluated the prognostic value of AKI by using three different algorithms to calculate $\mathrm{sCr}$ increase: either as the difference between the highest value in the first $24 \mathrm{~h}$ after ICU admission and a pre-admission historical $(\triangle H I S)$ or an estimated $(\triangle E S T)$ baseline value, or by subtracting the ICU admission value from the sCr value $24 \mathrm{~h}$ after ICU admission ( $\triangle \mathrm{ADM})$. Different cut-off levels of s $\mathrm{Cr}$ increase $(0.1,0.2,0.3$, 0.4 and $0.5 \mathrm{mg} / \mathrm{dl}$ ) were evaluated.

Results: Mortality at 3 months, 1 and 2 years in AKI defined as $\triangle \mathrm{ADM}>0.3 \mathrm{mg} / \mathrm{dl}$ was $48.1 \%, 63.0 \%$ and $63.0 \%$ vs $27.7 \%, 39.8 \%$ and $47.6 \%$ in no AKI respectively (OR(95\%Cl): $2.42(1.06-5.54), 2.58(1.11-5.97)$ and $1.87(0.81-4.33) ; 0.3 \mathrm{mg} / \mathrm{dl}$ was the lowest cut-off value that was discriminatory. When AKI was defined as $\Delta \mathrm{HIS}>0.3 \mathrm{mg} / \mathrm{dl}$ or $\Delta \mathrm{EST}>0.3 \mathrm{mg} / \mathrm{dl}$, there was no significant difference in mortality between AKI and no AKI.

Conclusions: The prognostic value of a $0.3 \mathrm{mg} / \mathrm{dl}$ increase in $\mathrm{s} C \mathrm{r}$, on mortality in sepsis, depends on how this $\mathrm{s} C \mathrm{r}$ increase is calculated. Only if the evolution of serum creatinine over the first $24 \mathrm{~h}$ after ICU admission is taken into account, an association with mortality is found.
\end{abstract}

Keywords: AKI, Sepsis, Critical illness, Prognosis, Diagnosis, Mortality

\section{Background}

There is growing evidence that Acute Kidney Injury (AKI) is an independent predictor of mortality rather than an innocent bystander. In cardiac surgery it has clearly been demonstrated that even small serum creatinine $(\mathrm{sCr})$ increases are associated with increased mortality risk [1-4]. It remains unclear if this also applies to sepsis.

There is continuing debate on the interpretation of the proposed AKI classification criteria [5-8], and several interpretations of the same AKI definitions continue to appear in the literature [9-12]. The most important issue in this debate relates to the way we calculate the $\mathrm{sCr}$ increase. The currently proposed practice to use the

\footnotetext{
*Correspondence: wim.vanbiesen@ugent.be

Renal Division, Ghent University Hospital, Nephrology section, 0 K12, University Hospital, De Pintelaan 185, B9000 Ghent, Belgium
}

highest creatinine value over a certain time span after ICU (Intensive Care Unit) admission does not take into account the evolution of $\mathrm{sCr}$ as a response to therapeutic interventions. Although this might not be problematic when "AKI" is used as a diagnostic classifier, it can have an influence on the prognostic value of the label "AKI".

The prognostic value of AKI, using a $0.3 \mathrm{mg} / \mathrm{dl}$ cut off value for sCr increase, as proposed by AKIN (Acute Kidney Injury Network), KDIGO (Kidney Disease Improving Global Outcomes) and ERBP (European Renal Best Practice) $[5,7,8]$, has not previously been validated in a prospective cohort of exclusively sepsis patients. These patients are particularly prone to capillary leak and fluid accumulation which influences the distribution volume of $\mathrm{sCr}$, potentially resulting in a delay in $\mathrm{sCr}$ increase due to dilution [13]. This might result in even smaller 
increases of serum creatinine being associated with mortality in sepsis.

We hypothesized that changing the way to calculate serum creatinine increase could impact the prognostic value of AKI. In this prospective cohort study, we evaluated the impact of using three different algorithms to calculate the $\mathrm{sCr}$ increase. One algorithm $(\triangle \mathrm{ADM})$ took into account the evolution of $\mathrm{sCr}$ by comparing the $\mathrm{sCr}$ value $24 \mathrm{~h}$ after ICU admission with the ICU admission value. The other two algorithms ( $\triangle \mathrm{HIS}$ and $\Delta \mathrm{EST}$ ) were based on the peak sCr value over the same time span, compared to either a historical baseline value ( $\triangle \mathrm{HIS})$ or an estimated baseline value $(\triangle \mathrm{EST})$. Additionally, we intended to explore the robustness of a $0.3 \mathrm{mg} / \mathrm{dl} \mathrm{sCr}$ increase in sepsis, by comparing its predictive value to that of either smaller or larger $\mathrm{sCr}$ increases. We hypothesized that in sepsis, maybe even smaller serum creatinine increases would be associated with mortality because of dilution due to fluid accumulation.

\section{Methods}

One hundred and ninety five consecutive adult patients (age $\geq 17$ years) with sepsis admitted to the intensive care unit (ICU) of the Ghent University Hospital between 12/01/2010 and 27/03/2011 were included in this prospective cohort study. Sepsis, severe sepsis and septic shock were defined according to the American College of Chest Physicians/Society of Critical Care Medicine Consensus Conference guidelines [14]. Exclusion criteria were: 1) ICU stay less than $24 \mathrm{~h}$ or withdrawal of therapy, 2) no bladder catheter, 3) patients treated with chronic hemodialysis, 4) patients with RRT need due to AKI upon ICU admission, 5) Age < 17 years, 6) a history of organ transplantation, 7) obstructive AKI and 8) no central line or arterial catheter. Survival status was assessed at ICU, at 3 months, 1 year and 2 years by JV, either by checking hospital records or by telephone interview with the family practitioner.

Patients who developed sepsis during their ICU stay were not considered for inclusion.

The study was approved by the ethical committee of the Ghent University Hospital. Written informed consent was obtained from the patient or their next of kin.

Three algorithms were used to calculate the $\mathrm{sCr}$ increase: 1) " $\Delta$ HIS", defined as the highest value within $24 \mathrm{~h}$ after ICU admission minus the value of a preadmission historical baseline; 2) " $\triangle \mathrm{EST}$ ", defined as the highest value $24 \mathrm{~h}$ after ICU admission minus an estimated baseline value obtained by solving the MDRD (Modification of Diet in Renal Disease) equation assuming a GFR (Glomerular Filtration Ratio) of $75 \mathrm{ml} / \mathrm{min} /$ $1.73 \mathrm{~m}^{2}$, as suggested by ADQI [6] and 3) " $\triangle \mathrm{ADM}$ ", defined as the value at $24 \mathrm{~h}$ after ICU admission minus the value at ICU admission. We also used different values of
$\mathrm{sCr}$ increase as threshold for AKI diagnosis $(0.1,0.2,0.3$, 0.4 , and $0.5 \mathrm{mg} / \mathrm{dl}$ ), to assess the robustness of the $0.3 \mathrm{mg} / \mathrm{dl} \mathrm{sCr}$ increase criterion in sepsis.

Blood samples for measuring $\mathrm{sCr}$ were collected at the moment of study inclusion (D0T0), four hours later (D0T4), the next morning at $6 \mathrm{AM}$ (D1) and daily at $6 \mathrm{AM}$ for the next four days. during the first five days after ICU admission, centrifuged immediately and frozen at $-80^{\circ}$ for later batch analysis, using an Isotope Dilution Mass Spectroscopy traceable method (Roche Diagnostics ${ }^{\circ}$. Once patients were on dialysis, serum creatinine values within study protocol were no longer measured.

Severity of illness was assessed by the APACHE (Acute Physiology and Chronic Health Evaluation) II score during the first $24 \mathrm{~h}$ after admission, with or without the renal score.

The $24 \mathrm{~h}$ fluid balance was registered for all patients to account for bias due to fluid dilution.

All sepsis patients admitted to ICU between 6 AM and 18 PM were included on the day of ICU admission. Patients admitted to ICU after 18 PM were included the following day at 6 AM. For all patients, 'Day 1' (D1 = the day following the inclusion day) starts at 6 AM following the day of inclusion. (Fig. 1) Since the time interval between D1 and ICU admission was the same in each individual patient for the three algorithms, this issue is not likely to have influenced our results. The mean time interval also approximates $24 \mathrm{~h}$ (mean $=26 \mathrm{~h})$. Additionally, if anything, having to deal with different time intervals between patients would have lowered our chances of demonstrating that including the evolution of serum creatinine in the AKI definition enhances the predictive performance of the label 'AKI', The latter because in those patients with a time interval less than $24 \mathrm{~h}$, there might not have been sufficient time to evaluate the response to fluid resuscitation yet.

\section{Statistical analysis}

Results are reported as medians and interquartile ranges (IQR) for continuous variables, unless otherwise specified. Discrete variables are reported as numbers and/ or percentages. All statistical analyses were performed using SPSS 19.

Chi square was used to asses a difference in prevalence in case of a dichotomous outcome. Results are reported as Odds ratio with $95 \%$ confidence intervals (OR; $95 \% \mathrm{CI}$ ). Student $t$ test was used to compare the means of normally distributed continuous variables whereas non parametric tests were used to compare the medians of not normally distributed continuous variables.

Logistic regression (3 months) and Cox regression ( 1 and 2 year) were performed in forward and backward mode, presenting age, gender, presence of pre-existing renal insufficiency (eGFR $<60 \mathrm{ml} / \mathrm{min}$ ) (CKD (Chronic 


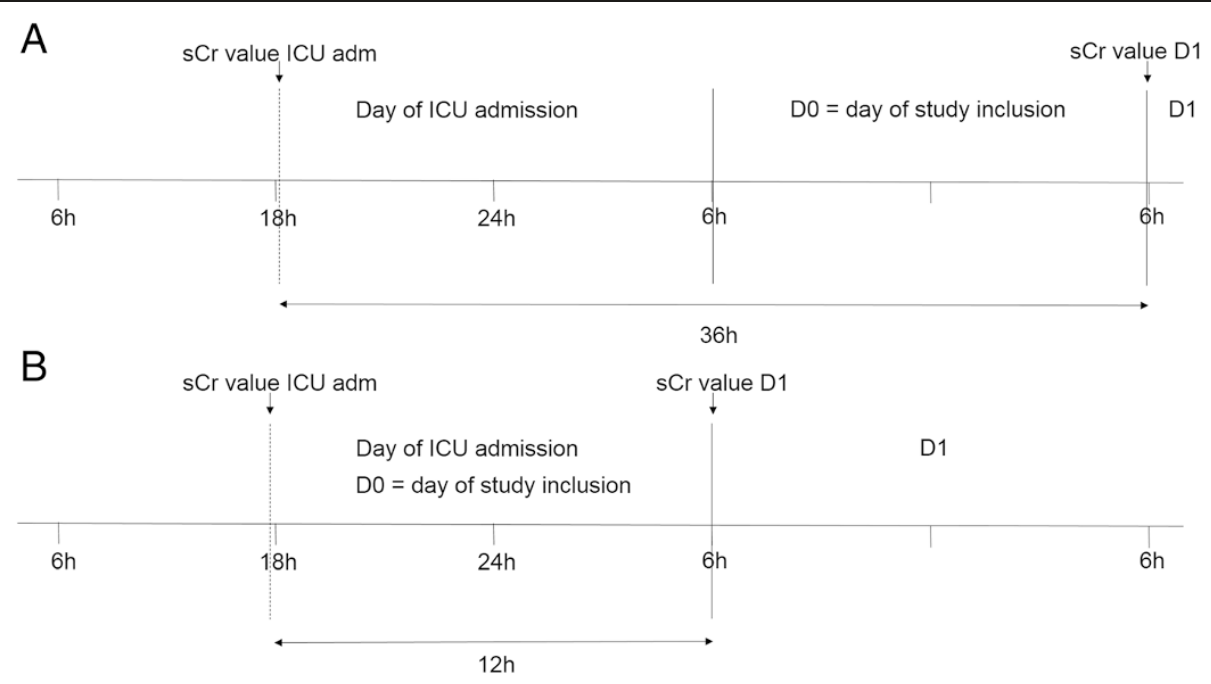

Fig. 1 Illustration of the method used for study inclusion. a: Graphic presentation of the time interval between the sCr value at D1 and the ICU admission value in case of a patient being admitted just after $18 \mathrm{pm}$. b: Graphic presentation of the time interval between the sCr value at D1 and the ICU admission value in case of a patient being admitted just before $18 \mathrm{pm}$

Kidney Disease)), APACHE II score, need for ventilation and $24 \mathrm{~h}$ fluid balance to the model as potential predictors for mortality. As additional parameter, AKI according to the different algorithms ( $\triangle \mathrm{HIS}, \triangle \mathrm{EST}$ and $\triangle \mathrm{ADM})$ and with different cut-offs for $\mathrm{sCr}$ increase for each algorithm (0.1, 0.2, $0.3,0.4$ and $0.5 \mathrm{mg} / \mathrm{dl} \mathrm{sCr}$ increase) were added to the model as a dummy code. Predictive performance was also assessed by comparing AUC ROC (Area Under the Curve of a Receiver Operating Characteristics Curve) analysis of the different models.

For the short term (3 months) mortality, we used a logistic regression model whereas for 1 and 2 years survival, we considered survival time as a continuous variable and used Cox Regression.

None of the patients was lost to follow-up. Two patients did not have a serum creatinine value available at D1 because they had died by then; as a consequence the $\triangle \mathrm{ADM}$ algorithm could not be used in these patients (since it is based on the value at D1 minus the ICU admission value). Another 8 patients did not have a serum creatinine value available at D1 because they were already on RRT by that time. These patients all had a rise in serum creatinine $>0.3 \mathrm{mg} / \mathrm{dl}$ before reaching the end of the time interval (=the value at D1), so they were assumed to have AKI according to the $\triangle \mathrm{ADM}$ algorithm although no actual value at D1 was available to calculate the serum creatinine increase. This paper complies with the STROBE criteria (see Additional file 1).

\section{Results}

\section{Descriptive patient data}

In this study, 195 consecutive patients with sepsis, severe sepsis and septic shock, were included. During the study period, 253 patients were considered for inclusion of whom 58 were excluded ( 18 for not having a bladder catheter, 13 because of RRT need upon ICU admission, 10 with a history of organ transplantation, 7 because of the decision to withdraw therapy, 5 for being treated with chronic dialysis, 3 who had ICU stay $<24 \mathrm{~h}, 1$ with obstructive AKI and 1 who did not have an arterial or central venous line). Nine (4.6 \%), 63 (32.3\%) and 123 (63.1 \%) had sepsis, severe sepsis and septic shock, respectively. Overall mortality rates at the ICU, three months, 1 year and 2 years were $23.1 \%, 31.3 \%, 43.6 \%$ and $50.3 \%$, respectively. Of the patients who needed RRT during their ICU stay $(n=27(13.8 \%))$, cumulative mortality rate during ICU stay was $55.6 \%$ (OR 5.75(2.44-13.53). Eighty-three percent of patients who were treated with RRT and survived ICU ( $n=10 / 12)$, survived up to two years. One patient treated with RRT died at three months and another died at year 1.

Demographics and relevant data for AKI vs no AKI according to the three different definitions $(\triangle \mathrm{ADM}$ $>0.3 \mathrm{mg} / \mathrm{dl}, \Delta \mathrm{HIS}>0.3 \mathrm{mg} / \mathrm{dl}$ and $\Delta \mathrm{EST}>0.3 \mathrm{mg} / \mathrm{dl})$ are presented in Table 1.

The prevalence of AKI varied according to the definition used. Based on $\Delta \mathrm{ADM}>0.3 \mathrm{mg} / \mathrm{dl}$ vs $\Delta \mathrm{HIS}>0.3 \mathrm{mg} / \mathrm{dl}$ and $\Delta \mathrm{EST}>0.3 \mathrm{mg} / \mathrm{dl}, 27(13.8 \%)$ vs $98(50.3 \%)$ and 89(45.6) patients were labelled as having AKI $(p<0.001)$. (Table 1).

Patients classified in the AKI vs no AKI group according to $\triangle \mathrm{ADM}>0.3 \mathrm{mg} / \mathrm{dl}$ had a greater severity of illness as demonstrated by a higher APACHE II score $(p=0.003)$, a higher need for invasive ventilation $(p<0.001)$ and a longer ICU stay $(p=0.009)$. When $\Delta$ HIS or $\Delta$ EST were used, there was a difference in APACHE II score in AKI vs no AKI but not in need for invasive ventilation or 
Table 1 Demographics in AKI vs no-AKI according to different definitions

\begin{tabular}{|c|c|c|c|c|c|c|c|c|c|}
\hline AKI definition & $\begin{array}{l}\Delta \mathrm{ADM}> \\
0.3\end{array}$ & & & $\Delta H I S>0.3$ & & & $\Delta \mathrm{EST}>0.3$ & & \\
\hline AKI/noAKI (n/\%) & $\begin{array}{l}\text { AKI (27/ } \\
13.8)\end{array}$ & $\begin{array}{l}\text { no AKI }(166 / \\
85.1)\end{array}$ & $\begin{array}{l}\mathrm{p} \\
\text { value }\end{array}$ & $\begin{array}{l}\text { AKI }(98 / \\
50.3)\end{array}$ & $\begin{array}{l}\text { no AKI (97/ } \\
49.7)\end{array}$ & $\begin{array}{l}\mathrm{p} \\
\text { value }\end{array}$ & $\begin{array}{l}\text { AKI }(89 / \\
45.6)\end{array}$ & $\begin{array}{l}\text { no AKI (106/ } \\
54.4)\end{array}$ & $\begin{array}{l}\mathrm{p} \\
\text { value }\end{array}$ \\
\hline$\%$ male & 66.7 & 61.4 & 0.6 & 67.3 & 57.7 & 0.17 & 65.2 & 60.4 & 0.49 \\
\hline Age $(y)($ mean/sd) & $66.2(10.7)$ & $60.7(15.6)$ & 0.08 & $62.6(14.1)$ & $60.2(15.8)$ & 0.28 & $65.1(13.5)$ & $58.2(15.5)$ & 0.001 \\
\hline APACHE ॥ & $27(9)$ & 22(9) & 0.003 & $25(8)$ & 19(9) & $<0.001$ & $25(8)$ & 20(9) & $<0.001$ \\
\hline Ventilation(n/\%) & $25 / 92.6$ & $80 / 48.2$ & $<0.001$ & $59 / 60.2$ & $47 / 48.5$ & 0.10 & $55 / 61.8$ & $51 / 48.1$ & 0.06 \\
\hline CKD(n/\%) & $7 / 25.9$ & $23 / 13.9$ & 0.11 & $18 / 18.4$ & $12 / 12.4$ & 0.25 & $25 / 28.1$ & $5 / 4.7$ & $<0.001$ \\
\hline $\begin{array}{l}\text { ICU admission serum creatinine } \\
(\mathrm{mg} / \mathrm{dl})\end{array}$ & $1.29(0.66)$ & $1.05(0.89)$ & 0.01 & $1.67(1.25)$ & $0.79(0.40)$ & $<0.001$ & $1.76(1.24)$ & $0.80(0.39)$ & $<0.001$ \\
\hline $\begin{array}{l}\text { Historical baseline creatinine (mg/ } \\
\text { dl) }\end{array}$ & $0.98(0.41)$ & $0.83(0.32)$ & 0.18 & $0.88(0.37)$ & $0.82(0.34)$ & 0.52 & $0.98(0.35)$ & $0.79(0.32)$ & 0.001 \\
\hline RRT need(n/\%) & $14 / 51.9$ & $13 / 7.8$ & $<0.001$ & $23 / 23.5$ & $4 / 4.1$ & $<0.001$ & $24 / 27$ & $3 / 2.8$ & $<0.001$ \\
\hline ICU LOS(d) in ICU survivors & $15(22)$ & $6(8)$ & 0.009 & $6(9)$ & $5(10)$ & 0.34 & $7(9)$ & $6(9)$ & 0.24 \\
\hline ICU Mort(n/\%) & $12 / 44.4$ & $31 / 18.7$ & 0.003 & $25 / 25.5$ & $20 / 20.6$ & 0.42 & $22 / 24.7$ & $23 / 21.7$ & 0.62 \\
\hline Mort at three months(n/\%) & $13 / 48.1$ & $46 / 27.7$ & 0.03 & $32 / 32.7$ & $29 / 39.9$ & 0.68 & $30 / 33.7$ & $31 / 29.2$ & 0.50 \\
\hline Mort at 1 year(n/\%) & $17 / 63$ & $66 / 39.8$ & 0.024 & $42 / 42.9$ & $43 / 44.3$ & 0.84 & $41 / 46.1$ & $44 / 41.5$ & 0.52 \\
\hline Mort at 2 years(n/\%) & $17 / 63$ & $79 / 47.6$ & 0.14 & $47 / 48$ & $51 / 52.6$ & 0.52 & $46 / 48.3$ & $51 / 51.9$ & 0.62 \\
\hline
\end{tabular}

AKI Acute kidney injury, $\triangle A D M>0.3=$ Serum creatinine increase $>0.3 \mathrm{mg} / \mathrm{dl}$ based on the difference between the value $24 \mathrm{~h}$ after admission and ICU admission, $\Delta \mathrm{HIS}>0.3=$ Serum creatinine increase $>0.3 \mathrm{mg} / \mathrm{dl}$ based on the difference between the highest value during the first $24 \mathrm{~h}$ after ICU admission and a historical baseline value, $\triangle E S T>0.3=$ Serum creatinine increase $>0.3 \mathrm{mg} / \mathrm{dl}$ based on the difference between the highest value during the first $24 \mathrm{~h}$ after ICU admission and an estimated baseline value, APACHE II Acute physiology and chronic health evaluation II score, CKD Chronic kidney disease, RRT Renal replacement therapy, ICU LOS Intensive care unit length of stay, Mort Mortality

length of ICU stay (Table 1). Based on $\triangle \mathrm{HIS}$ or $\triangle \mathrm{EST}$, there is a steady decrease in $\mathrm{sCr}$ vs the admission value in the AKI group over the following four days, as opposed to AKI according to $\triangle \mathrm{ADM}$ (Fig. $2 \mathrm{a}, \mathrm{b}$ and $\mathrm{c}$ ).

\section{Influence on prognostic value of different algorithms to calculate a serum creatinine increase of $0.3 \mathrm{mg} / \mathrm{dl}$ Entire study cohort}

In patients with AKI vs no AKI defined according to $\Delta \mathrm{ADM}>0.3 \mathrm{mg} / \mathrm{dl}$, ICU mortality, and three months, 1 year and 2 years mortality rates were $44.4 \%, 48.1 \%, 63 \%$ and $63 \%$ vs $18.7 \%, 27.7 \%, 39.8 \%$ and $47.6 \%$, respectively (OR 3.48(1.48-8.18), 2.42(1.06-5.54), 2.58(1.11-5.97) and 1.87(0.81-4.33)) (Table 1 and Fig. 3a).

When AKI was defined according to $\Delta \mathrm{HIS}>0.3 \mathrm{mg} / \mathrm{dl}$ or $\Delta \mathrm{EST}>0.3 \mathrm{mg} / \mathrm{dl}$, mortality rates were not different between AKI and no-AKI respectively at any of the time points (Table 1 and Fig. 3a).

\section{ICU survivors}

In ICU survivors $(n=150)$, mortality rates at three months, 1 year and 2 years in AKI vs no-AKI according to $\Delta \mathrm{ADM}>0.3 \mathrm{mg} / \mathrm{dl}$ were $6.7 \%, 33.3 \%$ and $33.3 \%$ vs $11.9 \%, 25.9 \%$ and $35.6 \%$ respectively (OR 0.53(0.07-4.32), $1.43(0.46-4.47)$ and $0.91(0.29-2.81)$ respectively). Based on $\Delta \mathrm{HIS}>0.3 \mathrm{mg} / \mathrm{dl}$, mortality rates were $9.6 \%, 23.3 \%$ and $30.1 \%$ vs $13 \%, 29.9 \%$ and $40.3 \%$ respectively (OR $0.71(0.26-1.98), 0.71(0.34-1.48)$ and $0.64(0.33-1.26))$. Based on $\Delta \mathrm{EST}>0.3 \mathrm{mg} / \mathrm{dl}$ these were $13.4 \%, 28.4 \%$ and $31.3 \%$ vs $9.6 \%, 25.3 \%$ and $38.6 \%$ in AKI vs no AKI respectively (OR 1.46(0.53-4.00), 1.17(0.57-2.42) and 0.73(0.37-1.44)) (Fig. 3b).

Thus with none of the above definitions $(\triangle \mathrm{ADM}>$ $0.3 \mathrm{mg} / \mathrm{dl}, \Delta \mathrm{HIS}>0.3 \mathrm{mg} / \mathrm{dl}$ or $\Delta \mathrm{EST}>0.3 \mathrm{mg} / \mathrm{dl})$ there was a significant difference in mortality rates between AKI and no AKI in septic patients who survived their ICU stay, either at three months, 1 year and 2 years.

Also other variants of calculating $\Delta \mathrm{sCr}$ were assessed, which confirmed that in sepsis patients only the evolution of $\mathrm{sCr}$ as compared to admission $\mathrm{sCr}$ was prognostic for mortality (see Additional files 2, 3 and 4).

\section{Prognostic value for mortality of different cut-off values for serum creatinine increase}

Using the different algorithms to calculate increase of sCr $(\triangle \mathrm{ADM}, \triangle \mathrm{HIS}, \triangle \mathrm{EST})$ and different cut-off levels for that increase $(0.1 \mathrm{mg} / \mathrm{dl}$ to $0.5 \mathrm{mg} / \mathrm{dl}$ with increments of $0.1 \mathrm{mg} / \mathrm{dl}$ ), we found that in univariate analysis an increase in $\mathrm{sCr}$ of $0.3 \mathrm{mg} / \mathrm{dl}$ was the lowest robust cut-off value that was still associated with mortality at three months in the entire cohort (OR 2.42, 95 \% CI 1.06-5.54), but only if the difference in increase of $\mathrm{sCr}$ was based on $\triangle \mathrm{ADM}$ (Fig. 4a). At year 1 and 2 an increase in $\mathrm{sCr}$ of $0.3 \mathrm{mg} / \mathrm{dl}$ was also the lowest robust cut-off for prediction of mortality in the entire cohort, again only when the definition is based on $\triangle \mathrm{ADM}$ (RR 2.11(1.24-3.6) and $R R$ 


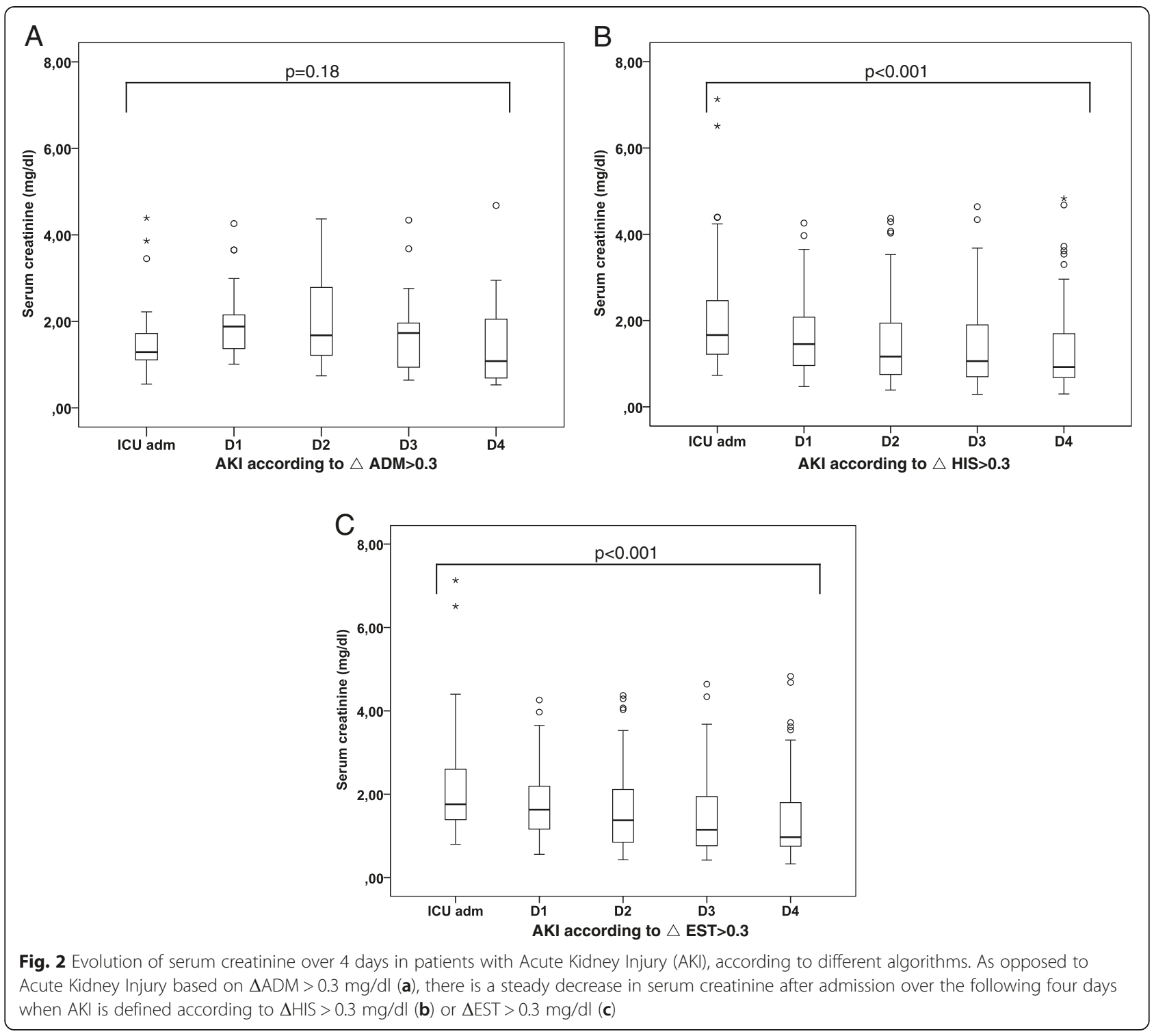

1.79(1.06-3.03) for mortality at 1 year and 2 years respectively) (Fig. $4 \mathrm{~b}$ and c). In multivariate analysis adjusting for the $24 \mathrm{~h}$ fluid balance, a $0.3 \mathrm{mg} / \mathrm{dl}$ increase in $\mathrm{sCr}$ remained the lowest robust value that was associated with mortality.

\section{Multivariate analysis for prediction of mortality}

In a logistic regression model adjusted, besides fluid balance, for age and gender, APACHE II score (OR per point: 1.07, $95 \%$ CI 1.02-1.13) and Need for Ventilation (OR 3.29, 95 \% CI 1.55-6.98) but not AKI according to $\triangle \mathrm{ADM}$, were independent predictors for mortality at three months (Table 2). Comparable results were obtained when the other definitions of AKI were used (Table 2). Using the APACHE II score without the renal score did not change these findings.
AUC ROC analysis confirmed that $\triangle \mathrm{ADM}>0.3 \mathrm{mg} / \mathrm{dl}$ did not add discriminatory value above APACHE II score and Need for Ventilation for prognostication of mortality at 3 months (AUC 0.71 without $\triangle \mathrm{ADM}>0.3 \mathrm{mg} / \mathrm{dl}$ and AUC 0.71 with $\triangle \mathrm{ADM}>0.3 \mathrm{mg} / \mathrm{dl}$ ).

In a Cox regression multivariate model applied to ICU survivors, only age was an independent predictor for mortality both at 1 year $(\mathrm{RR}=1.04,95 \% \mathrm{CI}$ : 1.01-1.07) and 2 years $(\mathrm{RR}=1.02,95 \% \mathrm{CI}: 1.002-1.045)$ (Table 3$)$. This suggests that longer term mortality in sepsis patients is more influenced by underlying comorbidity such as older age than by AKI or other parameters of acute severity of illness.

\section{Discussion}

This study demonstrates that the predictive value of an increase in serum creatinine of $0.3 \mathrm{mg} / \mathrm{dl}$, on mortality 


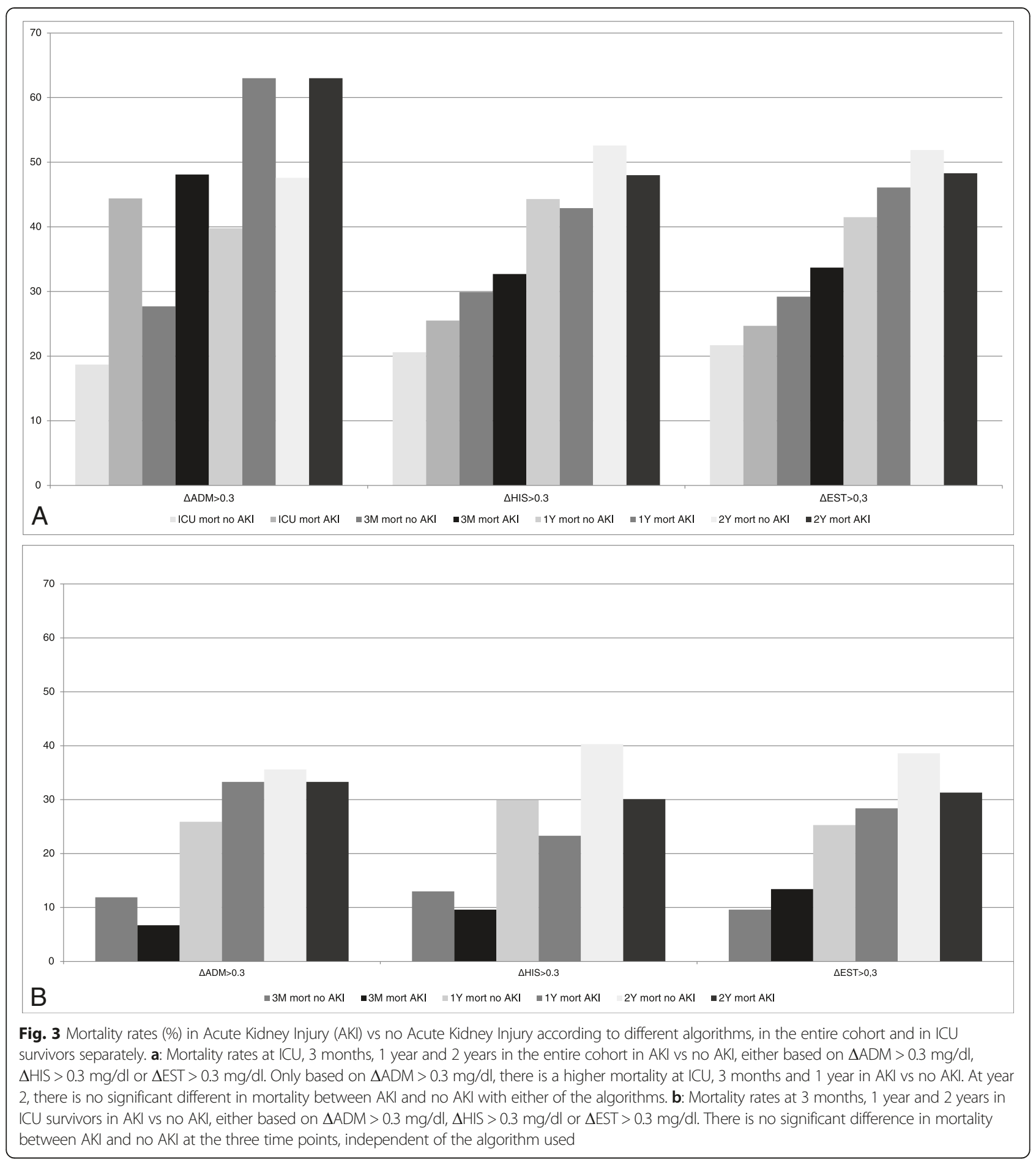

in sepsis, depends on how this $\mathrm{sCr}$ increase is calculated. Only if the evolution of $\mathrm{sCr}$ after ICU admission, rather than a peak $\mathrm{sCr}$ value over the same time span, is taken into account, an association with mortality is found. An increase in $\mathrm{sCr}$ of $0.3 \mathrm{mg} / \mathrm{dl}$ according to the ICU admission value is the lowest robust value still associated with mortality, confirming previous data in the cardiac surgery setting. This $0.3 \mathrm{mg} / \mathrm{dl}$ cut off remained robust even after adjustment for $24 \mathrm{~h}$ fluid balance. However, after adjusting for severity of illness, a $\mathrm{sCr}$ increase of $0.3 \mathrm{mg} / \mathrm{dl}$ was no longer associated with mortality.

Although the definition of AKI has become progressively more uniform since the introduction of RIFLE [6], uncertainty and debate on the methodology to calculate 


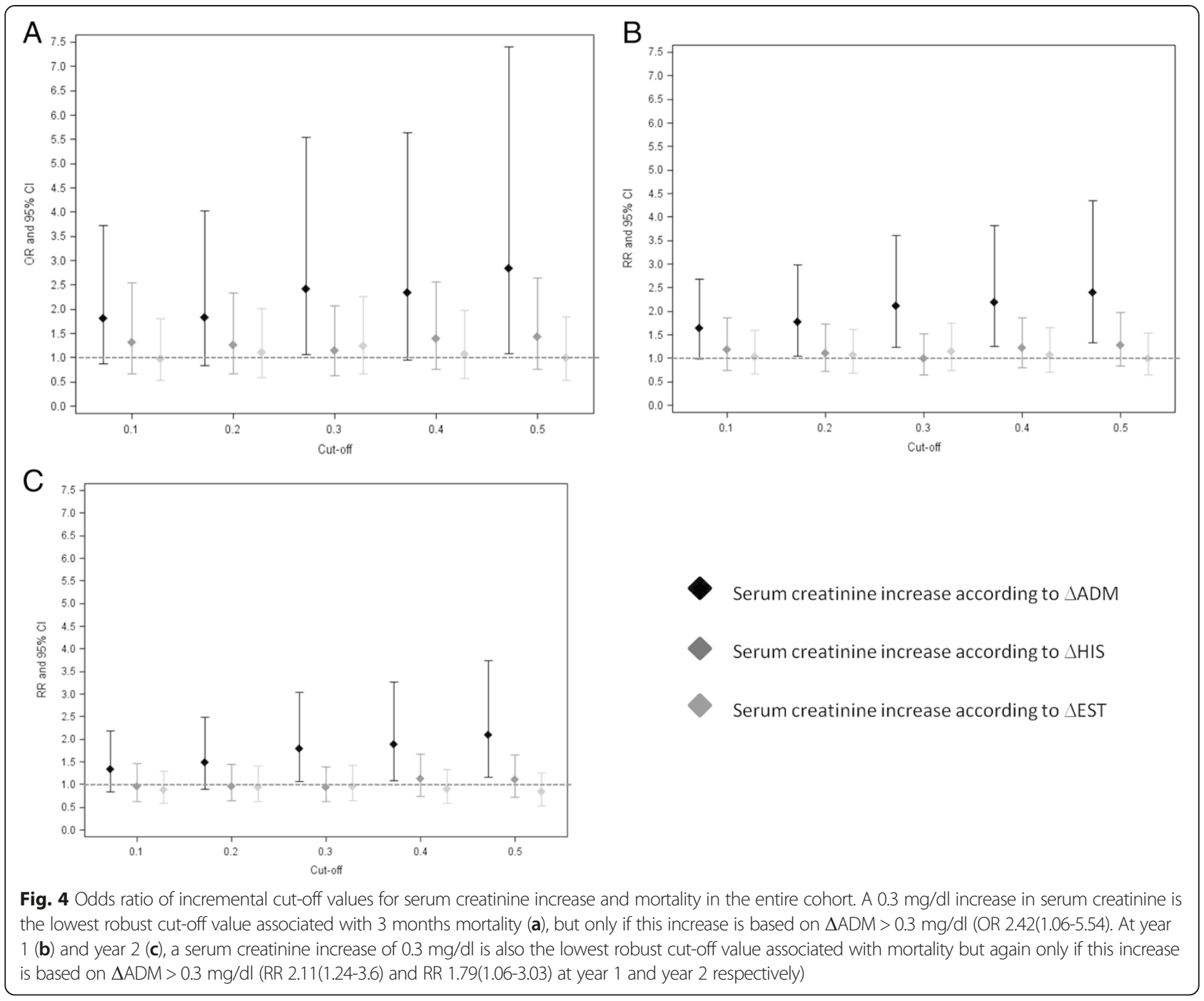

the $\mathrm{sCr}$ increase remains, and different interpretations are still appearing in the literature [9-12].

Most guidelines advocate to use the difference between the highest $\mathrm{sCr}$ value over a certain time span, and a pre admission historical baseline value $[15,16]$ or an estimated $\mathrm{sCr}$ value by solving the MDRD formula assuming a GFR of $75 \mathrm{ml} / \mathrm{min} / 1,73 \mathrm{~m}^{2}$ [17-20]. It has been demonstrated that the use of surrogate baseline $\mathrm{sCr}$ values can lead to misclassification by either under- or overestimation of AKI [15]. Siew et al. investigated the impact of using different surrogate baseline values in a large cohort of 4863 adults, on AKI diagnosis and outcome [16]. As in our cohort, they found that the incidence of AKI decreased by using the ICU admission $\mathrm{sCr}$ value as baseline versus a pre admission historical $\mathrm{sCr}$ value. They also demonstrated that mortality rates were different according to which surrogate value was used [16]. As in our study, mortality rates were highest when AKI was defined according to the admission value. However, Siew et al. used a cohort containing mainly non-critically ill patients (only $19 \%$ of patients were admitted to ICU) and only inhospital and 60 days mortality were evaluated, without adjustment for severity of illness [16].

The strategy of using the peak $\mathrm{sCr}$ value over a certain time span after admission does not allow to study the impact of the evolution of $\mathrm{sCr}$ after starting therapeutic interventions such as fluid resuscitation. In our cohort, AKI was associated with mortality, but only if based on the difference between the value $24 \mathrm{~h}$ after admission and the value at ICU admission and not if based on the peak value over the same time span compared to a historical or estimated baseline value. These findings suggest that the evolution of $\mathrm{sCr}$ in the first $24 \mathrm{~h}$ after ICU admission, and thus the potential response to fluid resuscitation, is most predictive for outcome which is in line with previous observations [21]. By taking into account the evolution of serum creatinine after ICU admission, those patients who experience a decrease in 
Table 2 Multivariate logistic regression for prediction of mortality at three months including different AKI definitions in the model

\begin{tabular}{|c|c|c|c|}
\hline & $\operatorname{Exp}(B)$ & $95 \% \mathrm{Cl}$ & $p$ value \\
\hline$\triangle A D M>0.3$ & 1.36 & $0.53-3.51$ & 0.53 \\
\hline Age & 1.01 & $0.99-1.04$ & 0.28 \\
\hline Gender & 0.75 & $0.37-1.47$ & 0.39 \\
\hline APACHE ॥ & 1.07 & $1.02-1.13$ & 0.009 \\
\hline Need for Ventilation & 3.29 & $1.55-6.98$ & 0.002 \\
\hline Fluid balance over the first $24 \mathrm{~h}$ after ICU admission & 0.89 & $0.76-1.05$ & 0.17 \\
\hline$\Delta \mathrm{HIS}>0.3$ & 0.64 & $0.31-1.32$ & 0.23 \\
\hline Age & 1.01 & $0.99-1.04$ & 0.35 \\
\hline Gender & 0.68 & $0.34-1.35$ & 0.27 \\
\hline APACHE ॥ & 1.09 & 1.03-1.15 & 0.002 \\
\hline Need for Ventilation & 3.32 & $1.60-6.89$ & 0.001 \\
\hline Fluid balance over the first $24 \mathrm{~h}$ after ICU admission & 0.92 & $0.79-1.07$ & 0.28 \\
\hline$\Delta \mathrm{EST}>0.3$ & 0.66 & $0.32-1.36$ & 0.26 \\
\hline Age & 1.01 & $0.99-1.04$ & 0.26 \\
\hline Gender & 0.69 & $0.35-1.38$ & 0.29 \\
\hline APACHE ॥ & 1.09 & 1.03-1.15 & 0.002 \\
\hline Need for Ventilation & 3.32 & $1.60-6.87$ & 0.001 \\
\hline Fluid balance over the first $24 \mathrm{~h}$ after ICU admission & 0.92 & $0.78-1.07$ & 0.27 \\
\hline
\end{tabular}

$\triangle A D M>0.3=$ Serum creatinine increase $>0.3 \mathrm{mg} / \mathrm{dl}$ based on the difference between the value $24 \mathrm{~h}$ after admission and ICU admission, APACHE I/ Acute physiology and chronic health evaluation II score, ICU Intensive care unit, $\triangle \mathrm{HIS}>0.3=$ Serum creatinine increase $>0.3 \mathrm{mg} / \mathrm{dl}$ based on the difference between the highest value during the first $24 \mathrm{~h}$ after ICU admission and a historical baseline value, $\Delta \mathrm{EST}>0.3=$ Serum creatinine increase $>0.3 \mathrm{mg} / \mathrm{dl}$ based on the difference between the highest value during the first $24 \mathrm{~h}$ after ICU admission and an estimated baseline value

Table 3 Multivariate cox regression analysis for prediction of mortality at 1 year and 2 years in ICU survivors

\begin{tabular}{|c|c|c|c|}
\hline 1 year mortality in ICU survivors & $\operatorname{Exp}(B)$ & $95 \% \mathrm{Cl}$ & $p$ value \\
\hline$\overline{\text { Age }}$ & 1.04 & $1.01-1.07$ & 0.004 \\
\hline Creatinine day 1 & 0.69 & $0.38-1.26$ & 0.23 \\
\hline CKD & 1.66 & $0.70-3.94$ & 0.26 \\
\hline$\Delta \mathrm{ADM}>0.3$ & 1.60 & $0.48-5.31$ & 0.44 \\
\hline Need for Ventilation & 1.16 & $0.59-2.29$ & 0.67 \\
\hline Gender & 0.65 & $0.32-1.31$ & 0.23 \\
\hline APACHE ॥ & 1.01 & $0.96-1.07$ & 0.59 \\
\hline Fluid balance over the first $24 \mathrm{~h}$ after ICU admission & 0.91 & $0.76-1.09$ & 0.28 \\
\hline \multicolumn{4}{|l|}{2 years mortality in ICU survivors } \\
\hline Age & 1.02 & $1.002-1.045$ & 0.03 \\
\hline Creatinine day 1 & 0.48 & $0.26-0.86$ & 0.01 \\
\hline CKD & 2.06 & $0.94-4.48$ & 0.07 \\
\hline$\Delta \mathrm{ADM}>0.3$ & 1.35 & $0.43-4.25$ & 0.61 \\
\hline Need for Ventilation & 1.44 & $0.79-2.60$ & 0.23 \\
\hline Gender & 0.68 & $0.37-1.24$ & 0.20 \\
\hline APACHE ॥ & 1.04 & $0.99-1.08$ & 0.10 \\
\hline Fluid balance over the first $24 \mathrm{~h}$ after ICU admission & 0.91 & $0.78-1.06$ & 0.21 \\
\hline
\end{tabular}

ICU Intensive care unit, CKD Chronic kidney disease, $\triangle A D M>0.3=$ Serum creatinine increase $>0.3 \mathrm{mg} / \mathrm{dl}$ based on the difference between the value $24 \mathrm{~h}$ after admission and ICU admission, APACHE II Acute physiology and chronic health evaluation II score 
serum creatinine under fluid resuscitation are no longer classified as having AKI which translates in a lower number of AKI cases compared to using the peak serum creatinine value over the same time period. It allows us to differentiate patients who are generally sicker and have more severe AKI and hence a worse outcome, from those with less severe AKI, responding to fluid resuscitation.

It is generally accepted that AKI is associated with increased mortality [22-24]. Bagshaw et al. performed a retrospective interrogation of prospectively included patients with sepsis, septic AKI and non-septic AKI. Sepsis, septic AKI and non-septic AKI were all found to be significantly associated with poor outcome. However, authors only looked at short term mortality (28 days and hospital mortality) and no data on RRT need were available, so it is unclear whether the effect on mortality was mainly driven by RRT need [23].

Despite this generally accepted association between AKI and mortality, the topic is still also a matter of debate, even in the non-critically ill. In a population based study of AKI, no association between AKI and outcome was found [25]. A higher risk for chronic dialysis need, but not mortality, was found in a large cohort of ICU survivors [26]. However, several reports indicated that the duration of AKI is highly predictive of mortality [27], an aspect that was not evaluated in the current study. This might explain why in our cohort the diagnosis of AKI was no longer independently associated with mortality after adjustment for severity of illness. Our data indicate that the response to treatment in the first $24 \mathrm{~h}$ after ICU admission also influences prognosis, probably by unveiling those who positively respond to volume resuscitation. Several older and more recent studies also demonstrated that the most important predictors for mortality were already present at admission to the ICU and included advanced age, the presence of infection, a past history of chronic diseases and the presence of other failing organs [28-32].

Although recent literature shows that even small increases in $\mathrm{sCr}$ are independently associated with mortality, these results are mainly obtained in cohorts of cardiac surgery patients, after coronarography and after myocardial infarction [1-4, 33-35]., In cardiac surgery, the relation between small increases in $\mathrm{sCr}$ and mortality might be amplified by the observation that in patients without $\mathrm{AKI}, \mathrm{sCr}$ levels are expected to decrease in the first $24 \mathrm{~h}$ after surgery because of fluid loading perioperatively, diluting the $\mathrm{sCr}$ value [36]. The association between small increases in $\mathrm{sCr}$ and poor outcome cannot necessarily be extrapolated to other conditions, such as sepsis. Sepsis patients are particularly vulnerable to capillary leak and fluid accumulation. Thus theoretically even smaller increases of $\mathrm{sCr}$ could be associated with mortality because of dilution of $\mathrm{sCr}$, and a delay in diagnosis [13]. However, according to the results of the current study, even after adjustment for $24 \mathrm{~h}$ fluid balance, a $0.3 \mathrm{mg} / \mathrm{dl}$ increase in $\mathrm{sCr} 24 \mathrm{~h}$ after ICU admission compared to the ICU admission value, seems to be the lowest robust threshold for increased risk in sepsis patients.

The strong points of this prospective study are the availability of longer term outcomes and the detailed patient information.

Our study is the first to consider that the evolution of $\mathrm{sCr}$ after start of therapy, rather than an absolute highest value over a certain time span is important with regard to outcome.

A limitation of this study is its observational nature and the fact that it is a single centre study describing a relatively small cohort of patients which enhances the chance of a type 2 error. We acknowledge that our results need to be validated in a larger cohort and are not necessarily generalizable to sepsis cohorts including patients with different severity of illness. However, the finding that taking into account the evolution of serum creatinine demonstrates a better association with mortality compared to only relying on a peak serum creatinine value over a certain time span for AKI diagnosis, does make sense from a pathophysiological point of view. Taking into account the evolution of serum creatinine allows for the identification of those who have more sever AKI, are more ill and consequently have a worse outcome.

By capturing AKI during the first $24 \mathrm{~h}$ after ICU admission we could incorporate the early response to fluid resuscitation in the $\triangle \mathrm{ADM}$ algorithm. Although by doing so we missed the AKI cases occurring after $24 \mathrm{~h}$ this is not likely to change our general message that AKI classification criteria should incorporate the evolution of $\mathrm{sCr}$ in response to fluid resuscitation. Also when we used a $48 \mathrm{~h}$ interval, our findings did not change (see Additional files 2, 3 and 4).

We did not include the urinary output as a prognostic criterion in this study. We demonstrated before that taking into account urinary output improved the diagnostic performance of RIFLE [37]. In several other studies, it was demonstrated that urinary output is associated with mortality in the critically ill $[38,39]$. In the current study, however, we wanted to evaluate the independent impact a change in the $\mathrm{sCr}$ criterion, as this is the most widely used criterion for prognostic modelling, especially in large (administrative) database cohorts [35, 40, 41].

Mortality rates in our cohort are low compared to what was reported in a recent study [42]. However, in general, mortality rates in sepsis have been reported to decline [42-45]. Mortality rates in our cohort of patients with sepsis might also be lower than in previous reports 
because we have a very good system in place in our ICU to alert physicians of pending AKI. Most of these alerts are induced by reduced urinary output [46]. It has been demonstrated before that AKI defined by oliguria has a better prognosis as AKI defined by the creatinine criterion [24].

\section{Conclusion}

The prognostic value of a $0.3 \mathrm{mg} / \mathrm{dl}$ increase in $\mathrm{sCr}$, on mortality in sepsis, depends on the algorithm to calculate this $\mathrm{sCr}$ increase. Only if the evolution of serum creatinine over the first $24 \mathrm{~h}$ after ICU admission is taken into account, an association with mortality is found. This $0.3 \mathrm{mg} /$ $\mathrm{dl}$ increase criterion remains robust, even after adjusting for 24 fluid balance. After adjustment for severity of illness, a sCr increase of $0.3 \mathrm{mg} / \mathrm{dl}$ is no longer associated with mortality in sepsis.

\section{Additional files}

\section{Additional file 1: STROBE checklist.}

Additional file 2: Odds ratio of incremental cut-off values for serum creatinine increase and 3 months mortality in the entire cohort.

Additional file 3: Relative Risk of incremental cut-off values for serum creatinine increase and 1 year mortality in the entire cohort.

Additional file 4: Relative Risk of incremental cut-off values for serum creatinine increase and 2 years mortality in the entire cohort.

\section{Abbreviations}

$\triangle A D M$ : The difference between the serum creatinine value $24 \mathrm{~h}$ after ICU admission and the ICU admission value; $\mathrm{ADQI}$ : Acute dialysis quality initiative; AKI: Acute kidney injury; AKIN: Acute kidney injury network; APACHE ॥ score: Acute physiology and chronic health evaluation II score; AUC ROC: Area under the curve of a receiver operating characteristics curve; CRP: C-reactive protein; CKD: Chronic kidney disease; (e)GFR: (estimated) glomerular filtration ratio; ERBP: European renal best practice; $\triangle E S T$ : The difference between the highest value serum creatinine value over the first $24 \mathrm{~h}$ after ICU admission and an estimated baseline value; $\triangle \mathrm{HIS}$ : The difference between the highest serum creatinine value over the first $24 \mathrm{~h}$ after $\mathrm{ICl}$ admission and a historical baseline value; ICU: Intensive care unit; IQR: Interquartile range; KDIGO: Kidney disease improving global outcome; LOS: Length of stay; MDRD: Modification of diet in renal disease; OR: Odds ratio; RIFLE: Risk, injury, failure, loss of kidney function and end-stage renal disease; RR: Relative risk; RRT: Renal replacement therapy; sCr: serum creatinine
\end{abstract}

\section{Competing interests}

The authors declare that they have no competing interests, financial or non-financial.

\section{Authors' contributions}

WVB and JV designed the study, wrote the protocol and conducted the statistical analysis. JV included the patients, collected the samples and the demographic data. JV and WVB wrote the first draft. NL, AD and RVH helped writing the draft and critically reviewed it. All authors read and approved the final manuscript.

\section{Acknowledgements}

The authors thank A De Jonghe, MA Waterloos, M Van Landschoot, C Danneels and B Martens for their technical assistance.

This work was funded by the Klinisch Onderzoeksfonds of the Ghent University Hospital, who had no part in the design of the study, the collection of the data or the draft of the paper.
Received: 15 March 2015 Accepted: 6 July 2015

Published online: 22 July 2015

\section{References}

1. Lassnigg A, Schmid ER, Hiesmayr M, Falk C, Druml W, Bauer P, et al. Impact of minimal increases in serum creatinine on outcome in patients after cardiothoracic surgery: do we have to revise current definitions of acute renal failure? Crit Care Med. 2008:36:1129-37.

2. Chertow GM, Burdick E, Honour M, Bonventre JV, Bates DW. Acute kidney injury, mortality, length of stay, and costs in hospitalized patients. J Am Soc Nephrol. 2005;16:3365-70.

3. Newsome BB, Warnock DG, McClellan WM, Herzog CA, Kiefe Cl, Eggers PW, et al. Long-term risk of mortality and end-stage renal disease among the elderly after small increases in serum creatinine level during hospitalization for acute myocardial infarction. Arch Intern Med. 2008;168:609-16.

4. Thakar CV, Christianson A, Freyberg R, Almenoff P, Render ML. Incidence and outcomes of acute kidney injury in intensive care units: a Veterans Administration study. Crit Care Med. 2009;37:2552-8.

5. Kidney disease: Improving Global Outcomes (KDIGO) Acute Kidney Injury Work Group. KDIGO Clinical Practice Guideline for Acute Kidney Injury. Kidney Int Suppl. 2012;2:1-138

6. Bellomo R, Ronco C, Kellum JA, Mehta RL, Palevsky P. Acute renal failure definition, outcome measures, animal models, fluid therapy and information technology needs: the Second International Consensus Conference of the Acute Dialysis Quality Initiative (ADQI) Group. Crit Care. 2004;8:R204-12.

7. Fliser D, Laville M, Covic A, Fouque D, Vanholder R, Juillard L, et al. A European Renal Best Practice (ERBP) position statement on the Kidney Disease Improving Global Outcomes (KDIGO) clinical practice guidelines on acute kidney injury: part 1: definitions, conservative management and contrast-induced nephropathy. Nephrol Dial Transplant. 2012;27:4263-72.

8. Mehta RL, Kellum JA, Shah SV, Molitoris BA, Ronco C, Warnock DG, et al. Acute Kidney Injury Network: report of an initiative to improve outcomes in acute kidney injury. Crit Care. 2007:11:1-8.

9. Fujii T, Uchino S, Takinami M, Bellomo R. Validation of the Kidney Disease Improving Global Outcomes criteria for AKI and comparison of three criteria in hospitalized patients. Clin J Am Soc Nephrol. 2014;9:848-54.

10. Leedahl DD, Frazee EN, Schramm GE, Dierkhising RA, Bergstralh EJ, Chawla $L S$, et al. Derivation of urine output thresholds that identify a very high risk of aki in patients with septic shock. Clin J Am Soc Nephrol. 2014;9:1-7.

11. Linder A, Fjell C, Levin A, Walley KR, Russell JA, Boyd JH. Small acute increases in serum creatinine are associated with decreased long-term survival in the critically ill. Am J Respir Crit Care Med. 2014;189:1075-81.

12. Machado MN, Nakazone MA, Maia LN. Prognostic value of acute kidney injury after cardiac surgery according to kidney disease: improving global outcomes definition and staging (kdigo) criteria. PLoS One. 2014;9, e98028.

13. Macedo E, Bouchard J, Soroko SH, Chertow GM, Himmelfarb J, Ikizler TA, et al. Fluid accumulation, recognition and staging of acute kidney injury in critically-ill patients. Crit Care. 2010;14:R82.

14. American College of Chest Physicians/Society of Critical Care Medicine Consensus Conference: definitions for sepsis and organ failure and guidelines for the use of innovative therapies in sepsis. Crit Care Med. 1992:20:864-74.

15. Zavada J, Hoste E, Cartin-Ceba R, Calzavacca P, Gajic O, Clermont G, et al. A comparison of three methods to estimate baseline creatinine for RIFLE classification. Nephrol Dial Transplant. 2010;25:3911-8.

16. Siew ED, Matheny ME, Ikizler TA, Lewis JB, Miller RA, Waitman LR, et al. Commonly used surrogates for baseline renal function affect the classification and prognosis of acute kidney injury. Kidney Int. 2010;77:536-42.

17. Bagshaw SM, George C, Bellomo R. A comparison of the RIFLE and AKIN criteria for acute kidney injury in critically ill patients. Nephrol Dial Transplant. 2008;23:1569-74.

18. Hoste EA, Clermont G, Kersten A, Venkataraman R, Angus DC, De BD, et al. RIFLE criteria for acute kidney injury are associated with hospital mortality in critically ill patients: a cohort analysis. Crit Care. 2006;10:R73.

19. Lopes JA, Fernandes P, Jorge S, Goncalves S, Alvarez A, Costa e Silva. Acute kidney injury in intensive care unit patients: a comparison between the RIFLE and the Acute Kidney Injury Network classifications. Crit Care. 2008:12:R110

20. Uchino S, Bellomo R, Goldsmith D, Bates S, Ronco C. An assessment of the RIFLE criteria for acute renal failure in hospitalized patients. Crit Care Med. 2006;34:1913-7. 
21. Levy MM, Macias WL, Vincent JL, Russell JA, Silva E, Trzaskoma B, et al. Early changes in organ function predict eventual survival in severe sepsis. Crit Care Med. 2005;33:2194-201.

22. Ricci Z, Cruz D, Ronco C. The RIFLE criteria and mortality in acute kidney injury: A systematic review. Kidney Int. 2008;73:538-46.

23. Bagshaw SM, George C, Bellomo R. Early acute kidney injury and sepsis: a multicentre evaluation. Crit Care. 2008;12:1-9.

24. Joannidis M, Metnitz B, Bauer P, Schusterschitz N, Moreno R, Druml W, et al. Acute kidney injury in critically ill patients classified by AKIN versus RIFLE using the SAPS 3 database. Intensive Care Med. 2009;35:1692-702

25. Ali T, Khan I, Simpson W, Prescott G, Townend J, Smith W, et al. Incidence and outcomes in acute kidney injury: a comprehensive population-based study. J Am Soc Nephrol. 2007;18:1292-8.

26. Wald R, Quinn RR, Luo J, Li P, Scales DC, Mamdani MM, et al. Chronic dialysis and death among survivors of acute kidney injury requiring dialysis. JAMA. 2009;302:1179-85.

27. Brown JR, Kramer RS, Coca SG, Parikh CR. Duration of acute kidney injury impacts long-term survival after cardiac surgery. Ann Thorac Surg. 2010;90:1142-8.

28. De Mendonca A, Vincent $J$, Suter PM, Moreno R, Dearden NM, Antonelli M, et al. Acute renal failure in the ICU: risk factors and outcome evaluated by the SOFA score. Intensive Care Med. 2000;26:915-21.

29. Ostermann $M$, Chang RW. Acute kidney injury in the intensive care unit according to RIFLE. Crit Care Med. 2007;35:1837-43.

30. Pereira MB, Zanetta DM, Abdulkader RC. The real importance of pre-existing comorbidities on long-term mortality after acute kidney injury. PLoS One. 2012;7, e47746.

31. Ponte B, Felipe C, Muriel A, Tenorio MT, Liano F. Long-term functional evolution after an acute kidney injury: a 10-year study. Nephrol Dial Transplant. 2008;23:3859-66.

32. Sasse KC, Nauenberg E, Long A, Anton B, Tucker HJ, Hu TW. Long-term survival after intensive care unit admission with sepsis. Crit Care Med. 1995;23:1040-7.

33. Ishani A, Nelson D, Clothier B, Schult T, Nugent S, Greer N, et al. The magnitude of acute serum creatinine increase after cardiac surgery and the risk of chronic kidney disease, progression of kidney disease, and death. Arch Intern Med. 2011;171:226-33

34. Lafrance JP, Miller DR. Acute kidney injury associates with increased long-term mortality. J Am Soc Nephrol. 2010;21:345-52.

35. Weisbord SD, Chen H, Stone RA, Kip KE, Fine MJ, Saul MI, et al. Association of increases in serum creatinine with mortality and length of hospital stay after coronary angiography. J Am Soc Nephrol. 2006;17:2871-7.

36. Ho J, Reslerova M, Gali B, Nickerson PW, Rush DN, Sood MM, et al. Serum creatinine measurement immediately after cardiac surgery and prediction of acute kidney injury. Am J Kidney Dis. 2012;59:196-201.

37. Vanmassenhove J, Glorieux G, Hoste E, Dhondt A, Vanholder R, Van BW. Urinary output and fractional excretion of sodium and urea as indicators of transient versus intrinsic acute kidney injury during early sepsis. Crit Care. 2013;17:1-10.

38. Macedo E, Malhotra R, Bouchard J, Wynn SK, Mehta RL. Oliguria is an early predictor of higher mortality in critically ill patients. Kidney Int 2011;80:760-7

39. Prowle JR, Liu YL, Licari E, Bagshaw SM, Egi M, Haase M, et al. Oliguria as predictive biomarker of acute kidney injury in critically ill patients. Crit Care. 2011;15:1-10.

40. Liangos O, Wald R, O'Bell JW, Price L, Pereira BJ, Jaber BL. Epidemiology and outcomes of acute renal failure in hospitalized patients: a national survey. Clin J Am Soc Nephrol. 2006;1:43-51.

41. Xue JL, Daniels F, Star RA, Kimmel PL, Eggers PW, Molitoris BA, et al. Incidence and mortality of acute renal failure in Medicare beneficiaries, 1992 to 2001. J Am Soc Nephrol. 2006;17:1135-42

42. Stevenson EK, Rubenstein AR, Radin GT, Wiener RS, Walkey AJ. Two decades of mortality trends among patients with severe sepsis: a comparative meta-analysis*. Crit Care Med. 2014;42:625-31.

43. Gaieski DF, Edwards JM, Kallan MJ, Carr BG. Benchmarking the incidence and mortality of severe sepsis in the United States. Crit Care Med. 2013;41:1167-74

44. Kaukonen KM, Bailey M, Suzuki S, Pilcher D, Bellomo R. Mortality related to severe sepsis and septic shock among critically ill patients in Australia and New Zealand, 2000-2012. JAMA. 2014:311:1308-16.
45. Vincent JL, Sakr Y, Sprung CL, Ranieri VM, Reinhart K, Gerlach H, et al. Sepsis in European intensive care units: results of the SOAP study. Crit Care Med. 2006;34:344-53.

46. Colpaert K, Hoste EA, Steurbaut K, Benoit D, Van HS, De TF, et al. Impact of real-time electronic alerting of acute kidney injury on therapeutic intervention and progression of RIFLE class. Crit Care Med. 2012;40:1164-70.

\section{Submit your next manuscript to BioMed Central and take full advantage of:}

- Convenient online submission

- Thorough peer review

- No space constraints or color figure charges

- Immediate publication on acceptance

- Inclusion in PubMed, CAS, Scopus and Google Scholar

- Research which is freely available for redistribution

Submit your manuscript at www.biomedcentral.com/submit 